\title{
Uso das mídias e redes sociais na consolidação do Partido Novo: As eleições 2018
}

\author{
Use of media and social networks in the consolidation of New Party: \\ The 2018 elections
}

\author{
André Silva de Oliveira \\ Rodolfo Silva Marques \\ Pedro Gustavo de Sousa Silva
}

\section{Resumo}

O presente artigo discute a estratégia do uso das redes sociais e das mídias sociais por parte do Partido Novo (NOVO), tendo como eixo cronológico as eleiçóes gerais de 2018. Parte-se da premissa de que as açóes contribuíram para os resultados eleitorais do partido no pleito. Nesse contexto, há uma breve apresentação das origens, da formação e trajetória da agremiação partidária, inclusive com sua base extraparlamentar. Identificadas as características e singularidades do NOVO, apresentam-se os conceitos de mídias e redes sociais. Na sequência, aprofunda-se a correlação das estratégias midiáticas do partido em 2018, em que elegeu 8 deputados federais, 11 deputados estaduais, um deputado distrital e um governador. Usam-se como métodos a revisão de literatura, a discussão conceitual e a análise dos dados do Tribunal Superior Eleitoral e das estratégias comunicacionais do NOVO. Identifica-se, de maneira clara, a importância das mídias digitais para o sucesso eleitoral do partido em 2018.

\section{Palavras-chave}

NOVO; Mídias; Redes Sociais; Eleiçôes 2018.

\section{Abstract}

This article discusses the strategy of the New Party (NOVO) use of social networks and social media, having as its chronological axis the 2018 general elections. It is based on the premise that the actions contributed to the party's election results in the election. In this context, there is a brief presentation of the origins, the formation and trajectory of the party association, including its extraparliamentary basis. Once the characteristics and singularities of NOVO are identified, the concepts of media and social networks are presented. Following this, the correlation of the party's media strategies in 2018 deepens, in which it elected 8 federal deputies, 11 state deputies, a district deputy and a governor. The literature review, conceptual discussion and analysis of data from the Superior Electoral Court and the communication strategies of NOVO are used as methods. It clearly identifies the importance of digital media for the party's electoral success in 2018.

\section{Keywords}

NOVO; Media; Social networks; Elections 2018. 


\section{Introdução}

O presente artigo, ao analisar o uso das mídias e redes sociais na estratégia do Partido Novo (NOVO) no pleito eleitoral de 2018, busca remontar também às origens, à representatividade e aos objetivos da agremiação dentro do contexto político brasileiro.

Um dos pontos importantes deste artigo, pois, refere-se à observação e à análise das origens, formação e trajetória do Partido Novo. Dentro do contexto das agremiaçóes partidárias, identifica, a priori, a desagregação da maior parte dos grupos políticos, com mudanças progressivas até à prevalência de um determinado modo de pensar.

No caso da agremiação partidária em questão, três aspectos são percebidos: a base partidária, a face pública e a direção nacional. A base partidária (party on the ground) contém os militantes, filiados e simpatizantes que podem multiplicar os ideais do NOVO. A face pública (party in public office) é o setor partidário presente nos Poderes Executivo e Legislativo, formada pelos ocupantes de cargos eletivos e pelos nomeados para cargos de confiança (assessores, secretários, ministros etc.). E a direção nacional (party in central office) é composta pelos integrantes das instâncias de comando do partido (tanto os dirigentes internos eleitos quanto os funcionários não-eleitos da burocracia $)^{1}$.

Nesse sentido, foi importante tanto identificar as características de origem do NOVO quanto observar traços de singularidade em relação aos demais partidos nacionais. No partido, o perfil social dos fundadores foi percebido em consonância com as informações sobre gênero, ocupação profissional, faixa etária, escolaridade e estado de origem.

Para ilustrar tal avaliação, a origem interna ou externa ao Parlamento e ao Governo foi verificada a partir dos mandatos eletivos ocupados pelos fundadores do partido. Se algum possuía mandato anteriormente, busca-se saber por qual sigla. E, para o enraizamento e para a estruturação da sigla, observa-se a inserção territorial por meio das comissóes provisórias e diretórios municipais e no resultado eleitoral da sigla nas eleições proporcionais.

De acordo com Braga e Pimentel Júnior (2011), os partidos brasileiros, tradicionalmente, não apresentam, em sua maioria, uma identidade partidária. Os autores também ressaltam que, a despeito das simpatias partidárias serem usadas na

\footnotetext{
${ }^{1} \mathrm{O}$ debate acerca das faces internas do partido (party on the ground, party in public office e party in central office) decorre do modelo do partido cartel de Katz e Mair (1995).
} 
6 | André Silva de Oliveira, Rodolfo Silva Marques e Pedro Gustavo de Sousa Silva

identificação de fatores para a decisão do voto entre os eleitores com maior escolaridade, foi possível observar que, mesmo entre os menos escolarizados, essa variável é também fundamental. Dentro desse contexto, novas agremiaçóes partidárias buscam arregimentar apoios e buscar maneiras outras de fazer política para agregar a capacidade de atrair eleitores (TAROUCO, 2012).

Desta forma, o presente artigo apresenta, na primeira seção, a exposição das origens do NOVO. Na sequência, há uma apresentação da correlação do partido com as instituições brasileiras. $\mathrm{Na}$ terceira seção, o uso das mídias e redes sociais como estratégia de comunicação e o desempenho eleitoral da agremiaçáo em questão. Por fim, as conclusôes, retomando as principais ideias apresentadas.

\section{As origens do NOVO}

Os caracteres organizativos de um partido dependem, dentre outros fatores, de como a organização nasceu e se consolidou. Por mais profundas que sejam as alterações ocorridas no partido ao longo do tempo, os traços do modelo originário permanecem. Nenhuma organização se desfaz por completo do próprio passado. Por isso, a análise organizativa requer a recuperação da dimensão histórica (PANEBIANCO, 2005).

O modelo originário consiste nos fatores que, em combinações variáveis, definem as características genéticas da organização. Os traços que sustentam a gênese do partido podem de fato exercer influência sobre as características organizativas, mesmo depois de décadas. Toda organização traz consigo a marca das principais decisões político-administrativas que a "modelaram" (PANEBIANCO, 2005).

$\mathrm{Na}$ fase genética, a identidade coletiva é definida basicamente em relação às metas ideológicas selecionadas pelos líderes. As metas ideológicas originárias definem o "território de caça" e circunscrevem a base social da organização, moldando a fisionomia organizativa na fase inicial. Com a institucionalização, os valores e objetivos dos líderes fundadores do partido são incorporados às exigências organizativas. Mesmo depois da consolidação, as metas ideológicas fornecem os recursos simbólicos de identidade e continuam modelando a imagem externa da organização, influenciando as relações de disputa-cooperação com outras organizações (PANEBIANCO, 2005).

Quando da fundação do NOVO, em 2011, não foi identificado um único parlamentar ou algum integrante que tivesse exercido mandato anteriormente. Parte expressiva dos fundadores é formada por profissionais, em geral, com ensino superior em áreas diversas, refletindo, por conseguinte, no viés ideológico liberal da sigla. 
Do ponto de vista estrutural, o NOVO almeja separar claramente a atuação da direçấo executiva do partido da sua representaçáo parlamentar, acreditando que desse modo possa adquirir uma gestão mais eficiente. De acordo com Madeira e Tarouco (2015), a grande fragmentação do sistema partidário no Brasil e a heterogeneidade das coligações, além de uma escolha eleitoral, em geral, feita a partir do personalismo, apresentam-se como aspectos que corroboram para dar suporte à ideia de que os partidos políticos brasileiros não contêm perspectivas ideológicas claras, com inconsistências programáticas. Dentro desse contexto, o NOVO procura romper o contexto hegemônico e impor uma agenda liberal na política e na economia, de acordo com os ideais que o compóem.

A direção do Partido Novo, aproveitando-se da perda de confiança pública nos partidos (BAQUERO e LINHARES, 2011), bem como nos controles institucionais sobre o uso do Caixa 2, defende o fim do financiamento público de campanha. É uma ideia com a qual pretende ter o apoio da opiniáo pública para a sua agenda liberal, demarcando, também aqui, outra divergência com os partidos estabelecidos. O fato de o NOVO não utilizar os recursos do Fundo Partidário, pelo menos até o ano de 2019, constitui a principal diferença de funcionamento da sigla em relação aos demais componentes do sistema partidário nacional.

Afinal, quem financia o NOVO? A literatura sobre financiamento dos partidos brasileiros indica um predomínio do recurso público diante das demais fontes de financiamento, independentemente do tamanho da agremiação partidária ou da posição no espectro ideológico. Isso pode ser verificado na prestação de contas anual entregue pelos partidos ao Tribunal Superior Eleitoral (TSE).

No Brasil, o dinheiro público é destinado tanto para custeio/manutenção dos partidos quanto para "aplicar" nas eleições. Em anos não eleitorais (anos ímpares), os recursos públicos constituem a principal fonte de sustentação financeira dos partidos. Em anos eleitorais (anos pares), o peso do dinheiro público na sustentação do partido reduz em função das doaçóes de campanhas.

A ideia de criar o NOVO surgiu entre empresários, médicos, advogados e outros profissionais do setor privado com o objetivo de participar da política sem vínculos com políticos tradicionais. Pelas regras da sigla, só pode se filiar ao Partido Novo quem tiver "ficha limpa". Com uma visão mais liberal da economia, já em seu 
primeiro discurso como candidato à presidência, João Amoêdo² defendeu rigor fiscal, privatizaçóes de todas as estatais e reforma da Previdência Social. Entre as suas propostas também estavam a desburocratização e o incentivo à iniciativa privada.

O NOVO se orgulha de sua origem marcadamente extraparlamentar e, portanto, do movimento espontâneo nascido na sociedade civil que o formou. No início dos anos 1980, o Partido dos Trabalhadores (PT) teve igualmente uma origem extraparlamentar, constituindo-se em "[...] um partido outsider em relação ao sistema político-institucional estritamente considerado” (REIS, 2014, p. 115-116).

O partido surgiu no Rio de Janeiro a partir das iniciativas de João Amoêdo, executivo advindo do mundo bancário e empresarial, cuja percepção indicou que as mudanças institucionais que imaginava somente poderiam ocorrer pela atividade político-parlamentar, considerando as notórias limitaçôes com que atuam as organizaçóes não governamentais nesse sentido. Ao analisar os motivos que levaram à criação do NOVO, Christian Lohbauer (2018, p. 24), ele mesmo um dos fundadores do partido, aponta que a decisão de João Amoêdo se apoiava na impossibilidade de fazer as mudanças institucionais em favor do cidadão-contribuinte fora do poder político: João Amoêdo decidiu propor um projeto que pudesse contribuir para a mudança do quadro político que fosse além de uma fundação beneficente, um instituto acadêmico, uma organização não governamental ou uma entidade sem fins lucrativos.

A literatura sobre partidos políticos no Brasil costuma anotar o surgimento extraparlamentar de partidos de esquerda e, antes do advento do PT, o caso mais evidente ou mencionado era o do Partido Comunista Brasileiro (PCB), de orientação ligada à antiga União Soviética e cuja penetração foi imensa no meio sindical e no campo político da esquerda, embora tivesse tido um curtíssimo período de existência legal. Por óbvio, a despeito dessa semelhança de origem extraparlamentar, a orientação ideológica do PT diverge frontalmente da agenda programática liberal

\footnotetext{
${ }^{2}$ Lohbauer (2018, p. 35) traça o seguinte perfil profissional de João Amoêdo: "João Amoêdo, 55, engenheiro civil pela UFRJ e bacharel em Administração pela PUC/RJ. Foi diretor executivo do Banco BBA-Creditansalt S.A. Em 1999, assumiu a gestão financeira do banco, a Fináustria, que foi vendida para o Banco Itaú. Em 2004, Amoêdo assumiu a vice-presidência do Unibanco e, em 2009, passou a ser membro do Conselho de Administração do Itaú-BBA, cargo que ocupou até 2015. É pré-candidato a Presidente da República em 2018”. Esse perfil sintético deixa entrever claramente que João Amoêdo não é um banqueiro ou sócio-proprietário de organização bancária, mas alguém que atuou no mercado bancário na condiçáo de executivo de CEO (Chef Executive Office), colocando-o tecnicamente como empregado, embora de alto nível.
} 
defendida pelo NOVO. No portal do Partido Novo na Internet, é possível verificar os princípios gerais do partido:

O NOVO foi fundado em 12 de fevereiro de 2011 por 181 cidadãos de 35 profissóes diferentes e oriundos de dez estados da Federação. Durante três anos e meio, nos dedicamos ao trabalho de divulgação dos nossos objetivos e valores e ao cumprimento das exigências legais para o registro do partido (NOVO, 2018a).

Os fundadores entendiam, então, que era preciso criar um novo partido político com nítido recorte liberal. Fiéis à tradição liberal que prioriza a defesa dos direitos dos indivíduos à frente dos interesses coletivos, os fundadores do NOVO idealizaram uma legenda que representasse em primeiro lugar o pagador de impostos, o produtor de riqueza, o cidadão indignado com a burocracia, enfim, todos os que supostamente tinham as iniciativas inviabilizadas pelo excesso de intervencionismo estatal no Brasil. Daí o relato oficial apontar que o grupo de fundadores do NOVO (2018a) havia concluído que "[...] um partido político seria a ferramenta democrática adequada para realizar as mudanças desejadas e necessárias".

Portanto, o discurso dos fundadores, liderados por João Amoêdo, teve como mote principal a defesa do cidadão-contribuinte em face da presumida voracidade tributária do Estado agigantado, apontado como obstáculo à geração de riqueza econômica. O NOVO seria, assim, "a ferramenta” para operar essa mudança políticoinstitucional rumo à implementação de uma agenda de recorte liberal. O NOVO costumeiramente enfatiza essa dicotomia entre o Estado grande e perdulário versus o cidadão-contribuinte oprimido pela carga tributária hiperbólica que lhe é historicamente imposta.

Os fundadores do NOVO viam a si mesmos como cidadãos indignados que se levantaram contra a fúria tributária estatal e a alegada má prestação dos serviços públicos, buscando, assim, estabelecer uma correlação entre os motivos fundantes do partido e os seus objetivos perenes de defender o sobrecarregado cidadãocontribuinte.

O simbolismo do discurso resta claro: o NOVO é uma agremiação de cidadãos livres e indignados que nasceu à margem das estruturas partidárias para trabalhar por outros cidadãos livres e indignados - a maioria da população - que se encontram debaixo de um voraz regime tributário que os impede de criar riqueza 
10 | André Silva de Oliveira, Rodolfo Silva Marques e Pedro Gustavo de Sousa Silva

econômica. Esse discurso foi usado pelo NOVO para apresentar-se na arena eleitoral como arauto da "nova política" em contraposição às velhas estruturas partidárias.

É evidente que a proposição em favor de uma agenda liberal que reduza o tamanho do Estado, cortando gastos para adequá-lo à política de responsabilidade fiscal, não poderia agregar atores políticos mais propensos a apelar à intervenção estatal como sindicalistas, representantes dos chamados movimentos sociais, representantes de minorias que se sentem desprotegidas etc., mas, sobretudo, integrantes oriundos das classes médias.

Não é nosso escopo discutir os eventuais acertos e equívocos da agenda marcadamente liberal do NOVO, mas, tão-somente, como foi salientado na Introdução, examinar os elementos constitutivos da formação originária do partido, além do uso das estratégias comunicacionais nas eleições de 2018.

Um brevíssimo ponto de inflexão cabe fazer aqui sobre o assunto. Alston et al. (2016) consideram que dois consensos foram forjados no Brasil nos últimos anos a partir da entrada em vigor do Plano Real, vale dizer, os governos passaram a levar a cabo simultaneamente políticas de responsabilidade fiscal e políticas de inclusão social. Não haveria, portanto, incompatibilidade ou incongruência na adoção simultânea das duas políticas públicas - uma de conteúdo macroeconômico e a outra de conteúdo social. Restaria, assim, extremamente difícil para qualquer governo, não importa o matiz ideológico, deixar de abraçar esses dois consensos consolidados.

Sintomaticamente, o NOVO, embora preconize uma gestão eficiente dos (limitados) recursos do Estado, não defende a erradicação das políticas de inclusão social, sugerindo o acerto da análise elaborada por Alston et al. (2016). Supóe-se que os substratos sociais presentes na composição originária do NOVO sejam oriundos, portanto, da classe média em sua maioria. São pessoas que, por convicção ideológica ou por não dependerem de nenhuma rede de proteção social estatal, expressam preferência ideológica pelo liberalismo político e econômico. Havia 181 pessoas no ato de fundação, sendo a maioria constituída por administradores, engenheiros, estudantes, advogados e médicos, seguidos de outras ocupaçóes. Nenhum - e a propaganda do NOVO sempre enfatiza este ponto central da sua trajetória inicial detinha mandato eletivo ou tinha tido vínculo partidário anterior, caracterizando, assim, sua matriz extraparlamentar.

Essa formação originária extraparlamentar do NOVO se constitui em uma novidade na literatura sobre partidos no Brasil não porque jamais tenha ocorrido - $\mathrm{o}$ PCB e, depois, o PT também tiveram uma trajetória inicial extraparlamentar -, mas porque surge da classe média com o objetivo de defender uma agenda liberal. Havia, 
decerto, outros partidos de recorte liberal em funcionamento, como, por exemplo, o Democratas (DEM), mas a intensa insatisfação com o sistema político formal provocou esse ponto de ruptura, permitindo o advento do NOVO (PEREIRA, 2015).

Tentando afastar-se do sistema de partidos - largamente afetados pelas anomalias do presidencialismo de coalizão -, o NOVO se recusa a fazer coalizóes, apresenta-se como partido outsider, acenando com a renovação da atividade política e a adoção de uma nova agenda econômica (BERTHOLINI e PEREIRA, 2017). O eventual êxito do caminho "sem atalhos" proposto pelo NOVO depende da confiança e apoio que os filiados depositarão na direção partidária, a presumida vanguarda que saberá tomar as decisóes certas, bem como submeter a representação política à disciplina e às regras estatutárias. Um partido de recorte nitidamente liberal que se converta eventualmente em um partido de massas com uma estrutura interna fortemente hierarquizada abre, assim, perspectivas interessantes de novos estudos, considerando, sobretudo, a singularidade do caso em face da literatura existente.

\section{O Partido Novo e as instituições}

Para verificar a origem externa do partido, é necessário sondar a trajetória dos fundadores. Quantos deles possuem ou possuíam mandatos eletivos? Se algum possuía mandato anteriormente, por qual sigla? Verificam-se tais questóes para os seguintes grupos: a) Lista de Fundadores (181 membros); b) Comissão Executiva Nacional Provisória; c) $1^{\circ}$ Diretório Nacional e; d) $1^{\circ}$ Executiva Nacional.

$\mathrm{Na}$ prática, os participantes da lista de fundação ocupam a Comissão Executiva e o Diretório. O NOVO enfatiza a sua origem espontânea e marcadamente extraparlamentar, porquanto nenhum dos seus 181 fundadores detinha no ato de criação da legenda mandato eletivo ou o havia exercido anteriormente. A narrativa oficial do partido ressalta essa distinção originária como uma vantagem competitiva em face dos demais partidos do sistema formal, desgastados com os escândalos de corrupçáo. A lista dos 181 fundadores do NOVO revela, além disso, que sua composição social é essencialmente oriunda da classe média urbana. Não há, assim, entre os fundadores, a presença de nenhum sindicalista, operário, campesino ou, ainda, político, líder ou não, no exercício do mandato ${ }^{3}$.

\footnotetext{
${ }^{3} \mathrm{Na}$ lista de fundadores, as exceçóes parecem residir nas presenças de Cecília Ribas Castello Branco, Emygdia Franca Vervloet e Marly Bezerra Mota que se declararam "do lar", da secretaria Leniza Ferreira, do gerente de cobrança Milton Henrique Toledo Brito e do motorista Luís Cláudio Laureano
} 
12 | André Silva de Oliveira, Rodolfo Silva Marques e Pedro Gustavo de Sousa Silva

Uma análise mais detida indica igualmente a presença de muitos possuidores de profissóes típicas da classe média urbana, tais como engenheiros (22), advogados (20) e médicos (16), mas de poucos empresários (9), ao menos os autodeclarados. João Amoêdo, idealizador do NOVO, figura na lista como engenheiro, embora tenha feito carreira no setor bancário, chegando a se converter em executivo (CEO).

Considerando que o percentual de empresários presentes no ato de fundação não ultrapassa a $5 \%$, bem como a presença predominante de profissóes clássicas (engenheiros, médicos, advogados, economistas etc.), pode-se afirmar que sua composição social originária predominante provém da classe média urbana, conforme já indicado, afastando potencialmente sua caracterização como um partido de natureza plutocrática, formado pelos estratos economicamente mais altos ou abonados da sociedade civil.

Além de se constituir em seu ato fundacional em um partido oriundo da classe média urbana, o NOVO apresenta um nítido recorte geográfico centrado no eixo Rio de Janeiro-São Paulo, com baixíssima presença de membros de outras unidades da Federação, sobretudo das regiôes mais pobres do país. Assim, há apenas um representante do Norte - o médico paraense Arthur Lobo - e um único do Nordeste - o administrador potiguar Cláudio Torres. O Centro-Oeste exibe três representantes, todos do Distrito Federal, e o Sul comparece igualmente com três membros - dois do Rio Grande do Sul e um do Paraná.

Obviamente, ainda é cedo para mensurar como esse evidente desequilíbrio entre os membros do pacto federativo no ato de fundação pode vir a afetar a expansão do partido em nível nacional. A estruturação inicial do NOVO concentrada na região Sudeste, especialmente no eixo Rio de Janeiro-São Paulo, sugere, de qualquer modo, que o partido deve se expandir a partir daqueles centros urbanos economicamente mais desenvolvidos.

A expansão eleitoral para as demais regióes do país, notadamente as economicamente mais debilitadas, como Norte e Nordeste, dependerá de um longo e difícil processo de estruturação com a criação de diretórios estaduais e municipais em unidades federativas com territórios vastos (como Pará, Amazonas, Bahia, Ceará, etc.), não raro com baixa densidade populacional, escassa escolaridade e incipiente classe média civicamente engajada.

da Silva, ocupaçóes e/ou profissóes que, a rigor, não os deslocam necessariamente para fora do segmento social tipificado como classe média urbana. 
Até a data de hoje, por exemplo, o Pará - que possui o maior colégio eleitoral do Norte, com 5.120.507 votantes (TSE, 2013), correspondendo a 3,614\% do eleitorado nacional - não conseguiu formar um Diretório Estadual, tendo apenas um Núcleo que foi instalado em janeiro de 2018. A efetiva penetração do NOVO nas regiôes do Brasil com menor Produto Interno Bruto (PIB) deve ser dificultada pelo próprio conteúdo econômico subjacente à mensagem principal do partido. $\mathrm{O}$ mote repetido reiteradamente - de que será retirado poder do governo para devolvê-lo ao cidadão por intermédio da redução dos tributos, corte de despesas e privilégios estatais, privatização das empresas públicas ineficientes etc., encontra forte apelo nas classes médias urbanas, mais bem informadas e, portanto, sensíveis à equação custobenefício decorrente do (mau) desempenho das atividades estatais.

De acordo com o Tribunal Superior Eleitoral (TSE), em 2019, 39,2\% do eleitorado brasileiro é analfabeto ou detém o ensino fundamental incompleto. A escassa escolaridade e a dependência de uma rede de proteção social estatal da população, sobretudo nas regiôes mais pobres do país, tornam, portanto, mais árida a tarefa do NOVO em promover sua agenda liberal, ao menos de forma maciça e num primeiro momento. Em razão desses obstáculos - alguns decorrentes da própria formação originária do NOVO, criando problemas de trajetória dependente (path dependence) -, é provável que a conquista do eleitorado nas regióes mais periféricas ocorra pelo êxito administrativo das prefeituras que venha a gerir. A eventual congruência entre boa gestão estatal e o discurso sobre racionalidade econômica reforçaria a percepção pública de que o partido protegeria, de fato, o cidadão mediano, importando-se com a defesa dos seus interesses e preferências.

Numa de suas resoluções, nominada de "gestão partidária independente", o NOVO (2018d, p. 1) pontua que "[...] a gestão partidária não pode ser feita por candidato ou ocupante de cargo eletivo, separação entre público e privado”. Além de buscar uma gestão eficiente do partido, essa separação bem demarcada entre as duas esferas evitaria potencialmente uma série de problemas constatados nas legendas mais consolidadas, como o que sucede com PSDB, MDB e PT, cujos representantes eleitos são igualmente dirigentes partidários, acumulando as atribuições do mandato com as da direção partidária. Tal situação tem trazido problemas tormentosos para os partidos quando seus principais líderes são, por exemplo, alvos de investigação criminal e/ou persecução judicial.

Outro mecanismo criado pelo NOVO (2018d, p. 1) que sugere o desejo de exercer o controle partidário efetivo sobre a representação parlamentar é a "vinculação 
14 | André Silva de Oliveira, Rodolfo Silva Marques e Pedro Gustavo de Sousa Silva

dos candidatos às suas propostas", significando a “[...] definição prévia do Compromisso de Gestáo e do Compromisso de Atuaçáo Legislativa prevendo metas a serem cumpridas". Esse mecanismo estabelece o compromisso expresso e a aceitação do monitoramento das açôes da representação pelo partido, restringindo, assim, sua liberdade de atuação.

Tais mecanismos estatutários talvez não impeçam a ocorrência de sérios atritos futuros entre a direçáo partidária e a representaçáo parlamentar, havendo o risco potencial de que a última, testada nas urnas e portadora de carisma político no sentido weberiano, reivindique maior autonomia em face do controle partidário. Somente um consenso robusto acerca da proteção dos princípios programáticos e ideológicos poderia eventualmente reforçar a unidade entre direção partidária e representação, evitando a emergência de choques mais traumáticos ou relevantes entre as duas esferas distintas.

Essa convergência da unidade partidária em favor da defesa dos princípios programáticos e ideológicos foi mais frequentemente verificada entre partidos de massa que se situam à esquerda do espectro político, notadamente nos partidos marxistas do início do século XX. O chamado "centralismo democrático", de recorte leninista, permitiu, especialmente na primeira metade do século $\mathrm{XX}$, quando o socialismo se encontrava em expansão, às elites partidárias emitir ordens que eram seguidas com grande fidelidade pelos filiados, sempre em nome da infalibilidade do ideário defendido. $\mathrm{O}$ centralismo democrático, que operava no interior dos partidos socialistas do tipo soviético, pode ser assim definido:

Os partidos de esquerda, durante muito tempo, foram muito autoritários. O que se praticava habitualmente era um centralismo burocrático muito estimulado pelas experiências do socialismo soviético. Todos os critérios, tarefas, iniciativas, linhas de ação eram decididos pela cúpula partidária, sem conhecimento nem debate com a militância, limitando-a a acatar ordens que nunca discutia e, muitas vezes, não compreendia. Uma atitude deste tipo parece cada vez mais intolerável para a maioria das pessoas (HARNECKER, 2013, p. 2).

A novidade aqui consiste em saber se um partido liberal poderá manter decerto, em longo prazo - a unidade partidária a partir da necessidade de proteger seus princípios programáticos e ideológicos.

Em contraposição a essa perspectiva, é importante ressaltar que o liberalismo é uma doutrina avessa à ideia de certezas ou infalibilidades históricas, como apontou 
Popper (1998) em obra seminal. A favor dessa ideia, está o fato de que o NOVO surgiu como outsider em relação ao sistema partidário vigente, assim como diante dos demais partidos de centro-direita e direita (PIERUCCI, 1987), que apresentam, em sua esmagadora maioria, quase nenhum ou nenhum compromisso com o ideário liberal (CODATO, BERLATO e BOLOGNESI, 2018).

O NOVO realiza processo seletivo, constituído de quatro etapas, para escolher os seus candidatos às eleiçôes proporcionais. O Estatuto dispóe de dispositivos que preveem que os candidatos e mandatários contarão com apoios e controles estruturais para orientá-los, com o fim de cumprir os objetivos do partido.

O artigo 52 do Estatuto do partido (2018b) indica que os "órgãos de apoio e controle" têm por desiderato desenvolver e assegurar uma "[...] atuação e governança que resultem na maior eficiência das atividades do NOVO, dos mandatários eleitos por ele e da qualidade do serviço público e da gestão governamental”. Os discursos de suas lideranças, a configuração estatutária etc., sugerem que a face dirigente tem a pretensão de exercer controle efetivo sobre a representação eleita, monitorando-a para que sua atuação não se afaste da agenda liberal proposta pelo partido. Vale, a esse propósito, notar que o NOVO proíbe as reeleiçôes consecutivas de seus representantes em cargos legislativos.

Ao fim dos mandatos atualmente em vigência (2019-22), será possível examinar com atenção até que ponto os membros da face pública do NOVO atenderam as expectativas estatutárias de conduzir os mandatos eleitos em conformidade com as deliberaçóes da direção partidária. A face pública governante (cujo expoente maior é o governador de Minas Gerais) e a face pública parlamentar (bancada de oito deputados federais) poderão ser observadas quanto ao grau de sintonia com as decisões das instâncias diretivas nacionais.

É o que o NOVO tipifica como "Limitação ao "carreirismo político", assim descrito numa de suas resoluções (2018d, p. 1): “[...] é vedado ao filiado eleito para cargo no Poder Legislativo que se candidate a mais de uma reeleição consecutiva”. Trata-se de uma tentativa - de resto, de implementação duvidosa - de permitir uma constante circulação de elites no interior do partido. De qualquer modo, uma carreira legislativa ascendente bem-sucedida que se inicie com o cargo de vereador e chegue ao Senado implica em exatos 20 anos de sucessivos pleitos sem postular a reeleição para nenhum dos cargos já conquistados.

Por fim, procurando se distinguir dos demais partidos que compõem o núcleo do sistema, o NOVO alardeia recusar os recursos oriundos do Fundo Partidário e do 
16 | André Silva de Oliveira, Rodolfo Silva Marques e Pedro Gustavo de Sousa Silva

Fundo Eleitoral, optando, em lugar disso, por subsistir com as contribuiçóes de seus filiados e doaçôes privadas. Parece evidente o esforço de trazer a ideia de mercado tão cara ao partido de nítido recorte liberal - para o árido campo do financiamento de campanhas, abalado, no caso brasileiro, pelos escândalos, primeiro do Mensalão e, depois, pelas revelações da Operação Lava Jato. O financiamento misto de campanhas ${ }^{4}$, que favorece especialmente os grandes partidos, não impediu a formação do chamado "Caixa 2", financiamento paralelo e oculto de partidos governistas por grandes empresas e empreiteiras em troca da obtenção de contratos bilionários junto às estatais, especialmente a Petrobras.

Esse conjunto de características distintivas e clara aposta na profissionalização da estrutura e práticas partidárias indica que o NOVO se aproxima da agremiação do tipo policy-seeking5. A repetição do discurso dos dirigentes do NOVO segundo o qual "não há atalhos" para chegar ao poder sugere que importa mais preservar a integridade da agenda liberal - e com crescimento eleitoral gradual, mas constante do que vencer outras eleiçôes majoritárias no curto prazo, celebrando coligações ou alianças com partidos com visóes distintas ou contaminados pelos escândalos de corrupção.

No conjunto, portanto, os traços distintivos do NOVO se amoldam ao modelo de partido do tipo policy-seeking descrito pela literatura: o tipo de partido policy-seeking é aquele que possui programas bem definidos, ideologias articuladas e que busca remodelar a agenda política com o objetivo de realizar mudanças substantivas em uma série de áreas. Geralmente, o partido dá mais prioridade às suas ideias e a seu programa do que às eleiçôes. No aspecto organizacional, conta com intensa participação de filiados/ativistas na vida partidária e com uma infraestrutura de apoio para o desenvolvimento de políticas (AMARAL, 2010, p. 112).

$\mathrm{O}$ controle efetivo sobre a representação remete curiosamente à tradição histórica dos partidos de esquerda a partir dos comandos que emanam do chamado "centralismo democrático", sob o pretexto de manter a unidade e a coerência

\footnotetext{
${ }^{4}$ Antes havia o financiamento misto (público e privado) de campanhas eleitorais, que foi modificado pelo acórdão proferido no bojo da Ação Direta de Inconstitucionalidade no 4.650, de 17.09.2015, pelo Supremo Tribunal Federal (STF), que proibiu o financiamento de empresas privadas às campanhas eleitorais a fim de evitar, como consta da ementa da referida decisão, a "[...] captura do processo político pelo poder econômico. 'Plutocratização' do prélio eleitoral. Limites de doaçóes por naturais e uso de recursos próprios pelos candidatos” (STF, 2015).

${ }^{5} \mathrm{O}$ debate sobre as características dos partidos policy-seeking, vote-seeking e office-seeking aparece em Wolinetz (2002).
} 
partidárias. Esse aspecto - controvertido sobretudo para um partido de recorte liberal - não parece sugerir, no entanto, que o NOVO queira instituir uma direção ou vanguarda iluminada capaz de ditar verticalmente ordens aos filiados. Desvela, antes, um anseio de fazer com que seus representantes não se afastem demasiadamente do ideário liberal, mantendo uma ação coerente que possa conquistar a confiança do eleitorado.

De qualquer modo, os atuais arranjos do NOVO evidenciam que, para manter a unidade dos filiados e a coerência programática, os dirigentes do partido detêm uma proeminência hierárquica sobre a representaçáo eleita, dispondo de mecanismos de controle fornecidos pelo Estatuto. De certo modo, e indo um pouco mais além, o perfil dos filiados do NOVO parece indicar que a busca da coerência partidária foi por eles assimilada, submetendo a representação ao escrutínio de controles formais e informais no exercício de suas atividades parlamentares. Mas este ponto relevante escapa ao foco de análise estabelecido no presente artigo e reclama estudos posteriores para elucidá-lo.

\section{Mídias e redes sociais: o NOVO nas eleições 2018}

Inicialmente, nesta seção, é importante considerar a diferença conceitual entre mídias sociais e redes sociais. Enquanto estas existiam e existem fora do ambiente virtual - e são maximizadas através da Internet -, aquelas são canais geradores de conteúdo que são fenômenos específicos da rede mundial de computadores (SAFKO e BRAKE, 2010).

De acordo com a autora Raquel Recuero (2010), as mídias sociais representam dinâmicas de criação de conteúdo e difusão da informação nas plataformas online. E tais conteúdos são fortalecidos através das redes sociais. Para Recuero (2009), dentro do contexto das mídias sociais, há aspectos importantes, como a mudança de paradigma na conversação, uma concentração menor de poder no processo de comunicação e uma maior circulação de informações. Mídias sociais são, portanto, um processo de geração de conteúdo a partir da descentralização da informação e a disseminação de ambos - conteúdo e informação - feita por qualquer pessoa (RECUERO, 2010). E as redes sociais, portanto, são canais compostos por organizaçóes e/ou pessoas que têm em comum alguns valores e objetivos, funcionando como grupos de interesse - e conectados. As redes sociais se fortalecem através da Internet, mas podem - e devem - existir fora dela. 
18 | André Silva de Oliveira, Rodolfo Silva Marques e Pedro Gustavo de Sousa Silva

A partir dessa conceituação, entre as mídias sociais, podem ser citadas o Twitter, os Blogs e o Instagram. Entre as redes sociais, podem ser identificadas, além do próprio Twitter e do Instagram, o WhatsApp e o já extinto Orkut. O Facebook, por exemplo, apresenta simultaneamente características de mídias e de redes sociais (BROGAN, 2012; REED, 2012).

E, usando esse mix de comunicação, em especial via Internet, o NOVO conseguiu mobilizar seus militantes e conquistar novas adesôes, além de fortalecer toda sua estratégia junto ao seu público-alvo, já definido na origem e na formação estatutária da agremiação. O pleito de 2018 foi o primeiro em que o NOVO teve candidato à Presidência da República. $\mathrm{O}$ engenheiro e administrador João Amoêdo, que representou o partido no pleito para presidente, declarou patrimônio à Justiça Eleitoral de R $\$ 425$ milhóes, o maior entre todos os candidatos (RAMALHO e CALGARO, 2018).

Os resultados eleitorais mostraram um grande sucesso do NOVO em suas estratégias de comunicação. Os números do Tribunal Superior Eleitoral mostraram, em 2018, a eleição de oito deputados federais, onze deputados estaduais, um deputado distrital (DF) e um governador (Romeu Zema, em Minas Gerais), além dos quase 2,7 milhôes de votos concedidos a Amoêdo no pleito presidencial. Nesse contexto, um dos fatores que motivou a realização da campanha do Partido Novo nas mídias e redes sociais foi o pouco tempo disponível em rádio e televisão na candidatura de João Amoêdo. Sem coligações ou alianças partidárias, Amoêdo teve disponíveis, nos blocos de propaganda nas mídias tradicionais, apenas 5 segundos diários - tempo totalmente irrisório para a apresentação de ideias.

Para além disso, não pôde participar dos debates públicos em emissoras de TV e Rádio, pelo fato de o seu partido, até então, não ter representação no Congresso Nacional - além de pouco ter aparecido nas pesquisas de intenção de voto. O quadro a seguir traz um panorama dos eleitos pelo Partido Novo em 2018. 
Quadro 1 - Políticos eleitos pelo NOVO em 2018

\begin{tabular}{|c|c|c|c|}
\hline Político eleito & Cargo & Estado & No de Votos \\
\hline Adriana Ventura & Deputada Federal & SP & 64.341 \\
\hline Alexandre Freitas & Deputado Estadual & $\mathrm{RJ}$ & 20.234 \\
\hline Alexis & Deputado Federal & SP & 45.298 \\
\hline Bartô & Deputado Estadual & MG & 31.991 \\
\hline Chicão Bulhôes & Deputado Estadual & $\mathrm{RJ}$ & 26.335 \\
\hline Daniel José & Deputado Estadual & SP & 183.480 \\
\hline Fábio Ostermann & Deputado Estadual & RS & 48.897 \\
\hline Gilson Marques & Deputado Federal & $\mathrm{SC}$ & 27.443 \\
\hline Giuseppe Riesgo & Deputado Estadual & RS & 16.224 \\
\hline Guilherme da Cunha & Deputado Estadual & MG & 24.792 \\
\hline Heni Ozi Cukier & Deputado Estadual & SP & 113.240 \\
\hline Júlia Lucy & Deputada Federal & DF & 7.655 \\
\hline Laura Serrano & Deputada Estadual & MG & 33.813 \\
\hline Lucas Gonzalez & Deputado Federal & MG & 64.022 \\
\hline Marcel Van Hattem & Deputado Federal & RS & 349.855 \\
\hline Paulo Ganime & Deputado Federal & $\mathrm{RJ}$ & 52.983 \\
\hline Ricardo Mellão & Deputado Estadual & SP & 27.150 \\
\hline Romeu Zema & Governador & MG & 6.963 .806 \\
\hline Sérgio Victor & Deputado Estadual & SP & 29.909 \\
\hline Tiago Mitraud & Deputado Federal & MG & 71.901 \\
\hline Vinicius Poit & Deputado Federal & SP & 207.118 \\
\hline
\end{tabular}

Fonte: Compilação dos autores, a partir de dados constantes em NOVO (2018e).

Após o pleito de 2018, partidos ideologicamente mais alinhados à direita, como o Partido Social Liberal (PSL, sigla do presidente da República, Jair Bolsonaro), Partido Republicano Brasileiro (PRB) e o NOVO tiveram um grande ingresso de novos filiados. Nos primeiros seis meses de 2019, o Partido Novo teve um grande crescimento relativo - 29\% - passando de 26,2 mil para 33,9 mil filiados. No sentido de estimular a filiação - e a contribuição financeira dos simpatizantes - a direção do NOVO informou que só autorizará candidaturas, nas eleiçóes municipais de 2020, nas cidades onde houver, pelo menos, 150 filiados (NOVO, 2018b).

O próprio modelo de adesão de interessados e simpatizantes pelo site do partido - <www.novo.org.br> - torna esse processo de admissão de filiados e de interação da direção partidária com os seus seguidores mais eficaz e eficiente. É um indicativo claro que o Partido Novo busca usar os recursos tecnológicos e midiáticos a favor de sua estratégia de relacionamento com seus seguidores. 
20 | André Silva de Oliveira, Rodolfo Silva Marques e Pedro Gustavo de Sousa Silva

É importante ressaltar, nesse processo, o bom desempenho do NOVO nas urnas, em 2018, com uma relaçáo muito clara com o uso eficiente das mídias digitais. Na campanha presidencial, João Amoêdo chegou a ter seus discursos e conteúdos diários serem distribuídos por militantes em até 70.000 destinos via WhatsApp

Essa mudança de eixo de estratégia comunicacional está associada não só a um uso mais efetivo dos recursos financeiros disponíveis - no caso do NOVO, a partir da receita oriunda de seus filiados e militantes -, mas também à presença e à relevância cada vez maior das mídias digitais na vida das pessoas, dos eleitores brasileiros. $\mathrm{O}$ grau de engajamento nas redes e mídias sociais a João Amoêdo e ao NOVO, em 2018, pode ser identificado na imagem abaixo.

Figura $1-\mathrm{O}$ peso dos candidatos nas urnas e nas redes

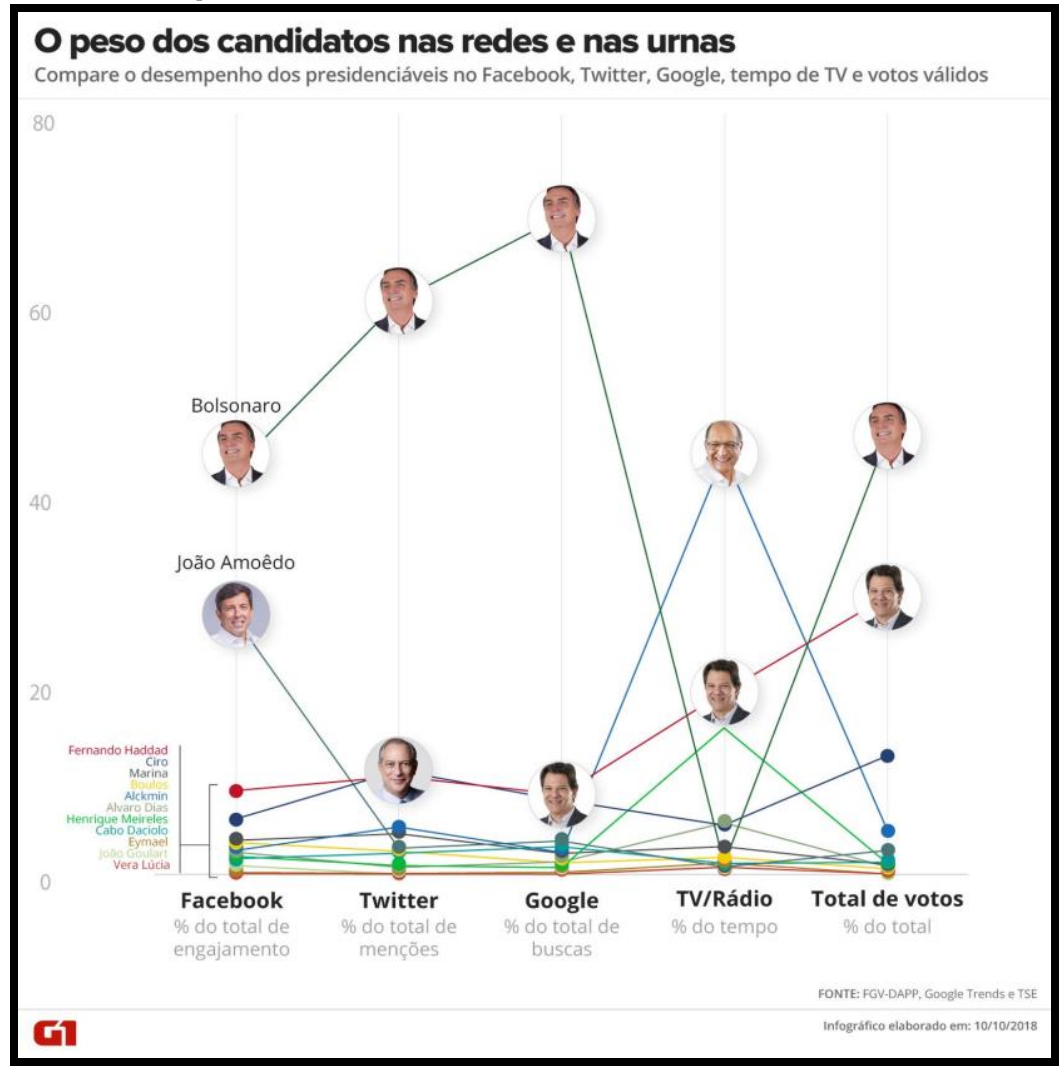

Fonte: Moreno e Vidigal (2018).

\footnotetext{
${ }^{6}$ Informaçôes disponíveis em <https://exame.abril.com.br/brasil/alta-de-amoedo-nas-pesquisas-animamilitancia-na-internet-e-fora-dela/>, com acesso em agosto de 2019.
} 
João Amoêdo (NOVO) teve, de acordo com a Figura 1, quase 27\% do total de vinculações e engajamentos no Facebook durante a campanha eleitoral no primeiro turno presidencial de 2018, com números muito similares ao do presidente eleito, Jair Bolsonaro (PSL). Os índices conquistados pelo candidato do NOVO são bem opostos, por exemplo, aos do candidato do PSDB, Geraldo Alckmin, que obteve apenas $2,5 \%$ do total de engajamento na rede, a despeito de ter $44 \%$ do tempo disponível, por exemplo, na propagada eleitoral gratuita no rádio e na televisão. Outro dado representativo em relaçáo à candidatura de Amoêdo em 2018 foi a questão de procuras pelo seu nome no buscador Google. Durante a campanha, em especial nas primeiras semanas de julho e agosto, o candidato do NOVO permaneceu entre os três mais procurados, reforçando o interesse dos internautas pelo seu nome, em especial pelo fato de ele ser pouco conhecido e aparecer raramente nas mídias tradicionais (MORENO e VIDIGAL, 2018).

E Amoêdo conseguiu também grande sucesso no Instagram e no sistema de multi-plataformas. $\mathrm{O}$ candidato do NOVO à presidência de República, durante o processo eleitoral, teve um avanço de cerca de 500 mil novos seguidores considerando-se o Twitter, o Instagram e o Facebook - números superiores a todos os demais candidatos (PARA GUSTAVO FRANCO..., 2018).

Dado um cenário de ínfimo espaço nos veículos oficiais da propaganda eleitoral, restou ao NOVO investir suas ações na comunicação via internet. Assim, as mídias e redes sociais claramente tiveram relevância no pleito de 2018, embora seja necessário entender que elas funcionaram em complementaridade com outros aspectos midiáticos e, principalmente, políticos e conjunturais.

\section{Considerações finais}

Diante do exposto, pode-se dizer que a estratégia de comunicação do NOVO nas eleiçóes de 2018 foi razoavelmente bem-sucedida, sobretudo o uso massivo das redes sociais, em especial o Facebook e o Twitter. Destaca-se que, no final de agosto de 2018, os vídeos de Amoêdo no Facebook já haviam sido visualizados 25 milhões de vezes (PRESIDENCIÁVEL JOÃO AMOÊDO..., 2018).

No primeiro turno, Joáo Amoêdo, principal fundador e candidato presidencial do partido, terminou o primeiro turno em quinto lugar, tendo recebido uma votaçáo correspondente a $2,5 \%$ do eleitorado. Essa votaçáo permitiu ao NOVO alcançar a cláusula de barreira e, mesmo sem ter participado dos grandes debates 
televisivos, ficar à frente de candidatos que possuíam uma exposição pública mais extensa e representavam legendas consolidadas como, por exemplo, Henrique Meirelles e Marina Silva, candidatos presidenciais do PMDB e da REDE e que obtiveram respectivamente $1,20 \%$ e $1 \%$ dos votos.

A origem e o perfil ideológico do Partido Novo se identificam diretamente com o uso intensivo das novas tecnologias e das estratégias mais modernas de comunicaçáo para com os seus eleitores - e tal tendência não deverá se modificar nos próximos pleitos. Até mesmo o partido já vem se pronunciando a respeito disso. $\mathrm{O}$ uso do site oficial da agremiação para gerar convocaçóes aos filiados e para a compra de produtos licenciados com as cores e com os símbolos do partido é o um fator gerador de mobilização e de comunicação.

É possível, também, visualizar claramente uma relação entre os ideais partidários, a estratégia de comunicação e o sucesso eleitoral em 2018. O engajamento dos filiados, o uso de caminhos tradicionais como a panfletagem nas ruas e, principalmente, o uso intenso das mídias e redes sociais foram essenciais para que a primeira grande participação em um processo eleitoral fosse encerrada com êxito para a agremiação partidária. A movimentação ideológica mais à direita foi percebida nas grandes votaçóes parlamentares para o NOVO e para o PSL, partido do presidente Jair Bolsonaro, que também teve grande êxito no uso das mídias e redes sociais (CODATO, BERLATO e BOLOGNESI, 2018).

Numa análise retrospectiva, o NOVO adotou o discurso não contra propriamente o sistema político - centrado no presidencialismo de coalizão com hiper-fragmentação partidária -, mas contra as práticas abusivas e/ou corruptas dos grupos da "velha política", apontadas como anomalias possíveis de erradicação. Ocorre, todavia, que o forte sentimento antipetista acabou por impulsionar a candidatura do deputado federal e capitão Jair Bolsonaro, que também se apresentara como um outsider ao sistema político, e, assim, a candidatura de Amoêdo foi, ao final, desidratada pela avalanche do voto útil. Bolsonaro (PSL), mesmo com pouquíssimo tempo de exposição no Horário Gratuito de Propaganda Eleitoral (HGPE), desbancou a polarização PT-PSDB que imperava nos últimos seis pleitos presidenciais. $\mathrm{O}$ reduzido tempo no HGPE foi compensando por uma estratégia eficiente na mobilização das novas mídias.

Como o partido insiste em não usar os recursos do Fundo Partidário que lhe são destinados, já que se apoia fundamentalmente na ideia de mercado aplicada à política, o crescimento do NOVO depende, em larga medida, do adequado e massivo manejo das redes sociais. Seguir apresentando-se como uma legenda, praticamente 
uma grife, moderna, vibrante, oriunda da sociedade e não do aparato estatal e, portanto, distinta das demais, se constitui em um objetivo crucial para a sobrevivência e eventual expansão do NOVO.

Toda predição sobre o futuro é, decerto, perigosa em política, mas pode-se inferir que o natural desgaste do exercício do poder - o governo de Minas Gerais está com o NOVO - obrigue o partido a modificar a sua estratégia de comunicação em tempo assaz breve. Afinal, e dito de outro modo, o NOVO não será "novo" por muito tempo.

André Silva de Oliveira é Doutor em Ciência Política pela Universidade Federal de Pernambuco (UFPE). E-mail: bandarraportugal@ig.com.br.

- Rodolfo Silva Marques é Doutor em Ciência Politica pela Universidade Federal do Rio Grande do Sul (UFRGS). E-mail: rodolfo.smarques@gmail.com.

- Pedro Gustavo de Sousa Silva é Doutor em Ciência Política pela Universidade Federal de Pernambuco (UFPE). E-mail: pgustavoss86@gmail.com.

\section{Referências}

ALSTON, Lee; MELO, M. André; MUELLER, Bernardo; PEREIRA, Carlos. Brazil in Transition Beliefs, Leadership, and Institutional Change. Princeton University Press, 2016.

AMARAL, Oswaldo E. do. Adaptação e resistência: o PT no Governo Lula entre 2003 e 2008. Revista Brasileira de Ciência Política, v. 4, p. 105-134, 2010.

BAQUERO, Marcello; LINHARES, Bianca. Por que os brasileiros não confiam nos partidos? Bases para compreender a cultura política (anti)partidária e possíveis saídas. Revista Debates, v. 5, n. 1, p. 89-114, jan./jun. 2011.

BERTHOLINI, Frederico; PEREIRA, Carlos. Pagando o preço de governar: custos de gerência de coalizão no presidencialismo brasileiro. Brazilian Journal of Public Administration, v. 51, n. 4, p. 528-550, 2017.

BRAGA, Maria do Socorro; PIMENTEL JÚNIOR, Jairo. Os partidos políticos brasileiros realmente não importam? Opiniāo Pública, v. 17, n. 2, p. 271-303, nov. 2011.

BROGAN, Chris. ABC das mídias sociais. São Paulo: Prumo, 2012. 
24 | André Silva de Oliveira, Rodolfo Silva Marques e Pedro Gustavo de Sousa Silva

CODATO, Adriano; BERLATTO, Fábia; BOLOGNESI, Bruno. Tipologia dos políticos de direita no Brasil: uma classificação empírica. Revista Análise Social, n. 229, p. 870-897, 2018. Disponível em: <https://doi.org/10.31447/as00032573.2018229.02>. Acesso em: 23 ago. 2019.

HARNECKER, Marta. Deve-se rechaçar o centralismo burocrático e praticar só o consenso? In: CLACSO - Consejo Latinoamericano de Ciencias Sociales, 2013, p. 1-3. Disponível em: $<$ http://bibliotecavirtual.clacso.org.ar/clacso/otros/20111023053855/central.pdf>. Acesso em: 31 out. 2019.

KATZ, Richard; MAIR, Peter. Changing models of party organization and party democracy: the emergence of the Cartel Party. Party Politics, v. 1, n. 1, p. 5-28, 1995.

LOHBAUER, Christian. Partido Novo: origens, ideias e objetivos. Interesse Nacional, ano 10, n. 40, p. 22-35, 2018.

MADEIRA, Rafael; TAROUCO, Gabriela. Os partidos brasileiros segundo seus estudiosos: análise de um expert survey. Revista Civitas, v. 15, n. 1, p. e24-e39, 2015. Disponível em: <http://dx.doi.org/10.15448/1984-7289.2015.1.18077>. Acesso em: 12 ago. 2019.

MORENO, Ana Carolina; VIDIGAL, Lucas. NA CAMPANHA e na urna, compare o desempenho dos presidenciáveis na internet, na TV e no resultado do $1^{\circ}$ turno. Portal G1, outubro de 2018. Disponível em: <https://g1.globo.com/politica/eleicoes/2018/eleicao-emnumeros/noticia/2018/10/12/na-campanha-e-na-urna-compare-o-desempenho-dos-presidenciaveisna-internet-na-tv-e-no-resultado-do-1o-turno.ghtml>. Acesso em 12 ago. 2019.

PANEBIANCO, Angelo. Modelos de partido: organização e poder nos partidos políticos. São Paulo: Martins Fontes, 2005.

PARA GUSTAVO FRANCO, economista do candidato, Amoêdo já passou do campo da dúvida para o da relevância. Exame, setembro de 2018. Disponível em: <https://exame.abril.com.br/brasil/altade-amoedo-nas-pesquisas-anima-militancia-na-internet-e-fora-dela/>. Acesso em 12 ago. 2019.

PARTIDO NOVO. Quem somos. 2018a. Disponível em <www.novo.org>. Acesso em: 12.ago. 2009. Estatuto. 2018b. Disponível em: <www.novo.org>. Acesso em: 12 ago. 2019.

Lista de fundadores. 2018c. Disponível em: <www.novo.org>. Acesso em: 12 ago. 2019.

Resoluçôes. 2018d. Disponível em: <www.novo.org>. Acesso em: 21 ago. 2019.

. Eleitos. 2018e. Disponível em: <https://novo.org.br/eleitos/>. Acesso em: 21 ago. 2019.

PEREIRA, Carlos. O custo dos governos petistas. 14 set. 2015. Disponível em: <https://cepesp.wordpress.com/2015/09/14/carlos-pereira-o-custo-dos-governos-petistas/>. Acesso em agosto de 2019, p. 1-2.

PIERUCCI, Antonio Flávio. As bases da nova direita. Novos Estudos, n. 19, 1987.

POPPER, Karl. A sociedade aberta e seus inimigos. Belo Horizonte: Itatiaia, 1998. v. 1 e 2.

PRESIDENCIÁVEL João Amoêdo busca 'desencantados' nas redes sociais. Veja, p. 1-2, 28 ago. 2018.

Disponível em: <https:/veja.abril.com.br/politica/presidenciavel-joao-amoedo-busca-desencantadosnas-redes-sociais/>. Acesso em: 12 ago. 2019.

RAMALHO, Renan; CALGARO, Fernanda. Nosso desempenho foi sensacional, diz Amoêdo sobre resultados do Partido Novo. Portal G1, outubro de 2019. Disponível em <https://g1.globo.com/politica/eleicoes/2018/noticia/2018/10/07/nosso-desempenho-foisensacional-diz-amoedo-sobre-resultados-do-partido-novo.ghtml>. Acesso em 12 ago. 2019.

RECUERO, Raquel. Redes sociais na Internet. Porto Alegre: Sulina, 2009. 
Mídia X Rede Social. 2010. Blog Raquel Recuero. Disponível em <www.raquelrecuero.com/arquivos/midiaxredesocial.html>. Acesso em 12 ago. 2019.

REED, Jon. Marketing online - como usar sites, blogs, redes sociais e muito mais. São Paulo: Lafonte, 2012.

REIS, Bruno. Da democracia participativa à pluralidade da representação: breves notas sobre a odisseia do PT na política e na ciência política brasileira. Revista Sociedade e Estado, v. 29, n. 1, p. 113-127, 2014.

SAFKO, Lon; BRAKE, David K. A bíblia da mídia social: táticas, ferramentas e estratégias para construir e transformar negócios. São Paulo: Blucher, 2010.

SUPREMO TRIBUNAL FEDERAL (STF). Ação Direta de Inconstitucionalidade n. ${ }^{\circ}$ 4.650, de 17 de setembro de 2015. Brasília: STF, 2015.

TAROUCO, Gabriela. Brazilian Parties According to their Manifestos: Political identity and Programmatic Emphases (Os partidos brasileiros segundo seus manifestos: identidade política e ênfases programáticas). Brazilian Political Science Review, v. 5, n. 1, p. 54-76, 2012. Disponível em: <https://papers.ssrn.com/sol3/papers.cfm?abstract_id=2173757>. Acesso em: 12 ago. 2019.

TRIBUNAL SUPERIOR ELEITORAL (TSE). Estatísticas do Eleitorado - Consulta por região/UF/município. 2019. Disponível em: <http://www.tse.jus.br/eleitor/estatisticas-deeleitorado/eleitorado>. Acesso em: 12 ago. 2019.

TRIBUNAL SUPERIOR ELEITORAL (TSE). Estatísticas do Eleitorado - Consulta por região/UF/município. 2013. Disponível em: <http://www.tse.jus.br/eleitor/estatisticas-deeleitorado/eleitorado>. Acesso em: 12 ago. 2019.

WOLINETZ, Steven. Beyond the Catch-All Party: Approaches to the Study of Parties and Party Organization in Contemporary Democracies. In: GUNTHER, Richard; MONTERO, Jose; LINZ, Juan. Political Parties: Old Concepts, New Challenges. Oxford: OUP, 2002. p. 136-165.

Texto recebido em 05 de setembro de 2019. Aprovado em 28 de outubro de 2019. 